\title{
El cuerpo y la nación: Sobre la muerte y el devenir
}

\author{
BeAtriz CorteZ \\ California State University, Northridge
}

\begin{abstract}
Resumen: El cuerpo es maleable, pero es percibido como el primer espacio que define nuestra identidad de forma fija, permanente, ya sin la posibilidad de imaginarnos un futuro fuera de los límites demarcados por esta identidad. Sin embargo, como lo señala Deleuze, una vida, antes de ser marcada por la subjetividad y definida como la vida de alguien, conlleva todas las posibilidades en el plano de inmanencia. En este sentido, es posible imaginarnos que el cuerpo también es la medida de nuestras posibilidades y es lo que nos permite involucrarnos en el proceso de transformación, movimiento, potencialidad, en el devenir. De forma paralela, desde el discurso nacionalista, la nación se define de forma rígida y permanente como una entidad ligada al territorio nacional. Sin embargo, el cuerpo es una metáfora de la nación. Así como devenir en otro es un proceso que nunca se completa pero que nos permite imaginarnos múltiples versiones de nosotros mismos, otras potencialidades en nuestros cuerpos, otros posibles futuros, así, el proceso de devenir en otra nación nunca está completo. Imaginarnos una nación que ya no esté definida de forma rígida nos podría permitir esbozar otros posibles futuros, otras posibles naciones en nuestro proceso colectivo del devenir.
\end{abstract}

Abstract: Even though the body is malleable, it is perceived as the first space that defines our identity in a fixed, permanent way, without the possibility of imagining our future outside the limits demarcated by that identity. Nevertheless, as Deleuze points out, a life, before being tainted by subjectivity and defined as somebody's life, carries with it all the possibilities in the plane of immanence. In that sense, it is possible to imagine that the body is also the measure of our possibilities, and that it is what allows us to be part of a process of transformation, potentialities, and becoming. In a parallel way, a nationalist discourse defines the nation in a rigid, permanent way as an entity that is bound to the national territory. However, the body is a metaphor of the nation. And just like becoming another is a process that is never completed but that allows us to imagine multiple versions of ourselves, other potentialities in our bodies, other possible futures, in the same way, the process of becoming another nation is never complete. To imagine a nation that is no longer defined in a rigid 
way could allow us to sketch out other possible futures, other possible nations in our collective process of becoming.

Palabras clave: cuerpo, nación, frontera, devenir, futuro, nomadismo

El cuerpo es un sitio donde tiene lugar una disputa política, un sitio donde se construye el nacionalismo, un lugar donde se ejerce la colonización y la explotación capitalista. Por un lado, el cuerpo es administrado a través de la implementación del biopoder, es decir, de la implementación de cierto tipo de poder que afecta los cuerpos de las personas y que representa a ciertos cuerpos como importantes, mientras
Keywords: Body, nation, border, becoming, future, nomadism

que a otros como irrelevantes. Es el tipo de poder que está dispuesto a sacrificar a ciertos cuerpos por el bienestar de otros. Al hablar del biopoder, Foucault explica cómo la muerte o la desaparición del otro, de los otros, a nuestro alrededor, es justificada por aquellos que se mantienen en el poder y que mantienen sus privilegios. Explicando este mecanismo, Foucault (2003) escribe:

\begin{abstract}
El hecho que el otro muera no significa simplemente que yo vivo en el sentido de que su muerte garantiza mi seguridad: la muerte del otro, la muerte de la raza defectuosa, de la raza mala (o de la degenerada, o de la anormal) es algo que hará la vida en general más saludable: más saludable y más pura. (p. 225)
\end{abstract}

Por consiguiente, el biopoder justifica la muerte del otro para poder garantizar la buena vida del sujeto del Estado. Es importante clarificar aquí que para Foucault, matar no tiene únicamente un sentido literal. También podría significar: "exponer a alguien a la muerte, incrementar el riesgo de la muerte para algunas personas, o simplemente, la muerte política, la expulsión, el rechazo, etc." (Foucault, 2003, p. 256). Forzar a las personas a migrar, no darles otra alternativa que migrar, es otra forma de eliminarlas de la nación.
Esta práctica de expulsar y marginar a parte de la población no es única en la historia centroamericana. Es un ejemplo más de una práctica común en espacios locales, municipales y nacionales en Centroamérica y en cualquier otro lado donde se pone en práctica la necesidad de eliminar a alguien del espacio público por el bien común. Por ejemplo, con frecuencia escuchamos sobre la necesidad de eliminar a la gente indeseada de los parques y las plazas para que estos espacios puedan estar disponibles para todos. Este sacrificio forzado impuesto sobre un porcentaje 
considerable de la población es presentado como una práctica que beneficia al resto de la población que sí es reconocido como parte del sujeto nacional. Otro ejemplo de ello es la forma en que parte de la población fue sacrificada cuando fue convertida en fuerza de trabajo (esclavizada a través de mecanismos del Estado, tales como las leyes de vagancia) para poder producir café de exportación y permitir a la nación que ingresara en el mercado mundial. Otro ejemplo es la forma como los escuadrones de la muerte, que surgieron durante las décadas de los 70 y 80 en este país, decidían sobre la vida y la muerte de parte de la población, particularmente de sus enemigos políticos. En este ejemplo, el biopoder funcionó a través de todo el cuerpo social en paralelo a la forma en que los miembros de la sociedad nazi tenían el poder de asesinar. Como Foucault (2003) lo explica:

Al final, todos en el Estado Nazi tenían poder sobre la vida y la muerte de sus vecinos, aunque solo fuera por la práctica de informar, que en realidad significaba deshacerse de los vecinos, o lograr que otros se deshicieran de ellos. (p. 259)

Comenzando la década de los 80, cuando las migraciones hacia los Estados Unidos, México y otros destinos se hicieron masivas, el cuerpo del migrante, en vez de constituirse como un objeto de control del Estado (es decir, de su Estado de origen), se convirtió en un objeto de control en ausencia a medida que desaparecía del panorama nacional. El cuerpo del migrante es controlado y administrado en la diáspora solamente para poder asegurar la continua recepción de remesas en forma paralela a cómo en el pasado el Estado operaba para garantizar la producción del café por medio de mano de obra forzada. El cuerpo del migrante deja de ser interesante para el Estado a medida que desaparece de la nación, pero su ausencia es celebrada porque continúa siendo una fuerza productiva para la nación. Por consiguiente, el Estado deja de reconocerle como un ciudadano, pero lo celebra como un hermano lejano, como un cuerpo ausente.

Sin embargo, en el momento en que el cuerpo del migrante reaparece, es deportado hacia acá, es repatriado y se convierte en una presencia que una vez más le asigna responsabilidad por su bienestar al Estado. El Estado aplica sobre este cuerpo nuevos mecanismos de control. Estos mecanismos pueden incluir la cárcel, el castigo basado en la ley o incluso la muerte de forma literal, porque un cuerpo repatriado es un cuerpo no deseado para la nación. Es un 
cuerpo que ya no tiene las características que hicieron posible su supervivencia: la posibilidad de enviar remesas hacia acá. Y por lo tanto, el cuerpo repatriado del migrante se convierte en blanco del Estado.

Por otro lado, el cuerpo del otro lado de la frontera, el cuerpo en los Estados Unidos, es el cuerpo de un migrante que es representado como invasor de un territorio soberano. Tanto el cuerpo como la nación son construidos a través del discurso como entidades independientes y separadas del mundo a su alrededor por una membrana impermeable; su piel o su frontera. A pesar de que el cuerpo está compuesto mayoritariamente por fluidos, no obstante de que sus poros y sus muchos orificios pueden ser contaminados, penetrados, transgredidos, y a pesar de su maleabilidad, su permanente estado de transformación y su permeabilidad, el cuerpo es imaginado como una entidad pura, aislada. Un proceso metafórico similar tiene lugar en la construcción discursiva de la nación, particularmente con respecto a la migración. Como lo señala Aimee Carrillo-Rowe (2004): "El cuerpo de la nación estadounidense es fundado" en "base a las ideas de la supremacía de los blancos". En el contexto de esta construcción, nos dice ella, "las contradicciones que surgen (...) son contenidas a través de la eliminación quirúrgica de las células cancerosas, para que la política del gran cuerpo blanco pueda permanecer intacta" (p. 116). Carrillo-Rowe presenta como ejemplo de esta construcción discursiva un discurso presentado el 25 de abril de 1994, por el aquel entonces gobernador de California, Pete Wilson. El discurso se titulaba "Asegurando Nuestras Fronteras Nacionales". Wilson argumentaba que la gente "se atraviesa la frontera a chorros (...) los agujeros en nuestra política federal han convertido a nuestras fronteras en un colador" (Wilson, 1994, p. 280), y señalaba la "condición porosa" de las fronteras. El ex gobernador decía que "asegurar las fronteras de nuestra nación es la única forma en que podremos asegurar el futuro que queremos para California" (Wilson, 1994, 282). El argumento de Carrillo-Rowe es que Wilson muestra una representación del espacio feminizado. Ella indica:

La mujer blanca funciona aquí como una metáfora del espacio nacional. Su violación metafórica produce una respuesta afectiva basada en la abyección de la movilidad de extranjeros criminales racializados. La producción de un espacio nacional feminizado, por consiguiente, surge de esta particular articulación de la inmovilidad migrante. (Carrillo-Rowe, 2004, p. 126) 
La frontera es imponente, cuando menos. Como un símbolo, la frontera representa esa pared impermeable, esa piel que contiene a la nación como resultado de la diagramación del territorio, del aire y del océano, como Deleuze y Guattari (1987) lo describen en Mil mesetas. Sin embargo, esta diagramación del espacio es inútil, pues la frontera sigue siendo permeable no solamente porque cientos de inmigrantes la cruzan todos los días, sino también porque el aire y el agua y todo lo que estos cuerpos contienen permea y penetra con su continuo fluir el espacio nacional que ha sido diagramado. Esto es particularmente visible en el parque llamado "Friendship Park" (Parque de la Amistad), el lugar donde la frontera entra en el Océano Pacífico entre San Diego y Tijuana. Allí, las aguas fluyen de un lado al otro de la frontera, mientras los pájaros dibujan sus rutas en el cielo, yendo y viniendo de México a los Estados Unidos sin ningún respeto hacia la frontera simbólica que separa a las dos naciones y que ingresa en el Océano Pacífico.

De manera similar, el cuerpo no es un sitio estático ni está aislado de su medio ambiente. El devenir del cuerpo es impactado por su maleabilidad, su transformación y la constante penetración de lo que le rodea. El cuerpo respira, tiene poros, está formado por líquidos y es afectado, después de todo, por las leyes de la dinámica de fluidos.
Como Spinoza nos ha enseñado, a través de la duración temporal de nuestra vida, el cuerpo se hace necesario para nuestro devenir. Sin embargo, como Deleuze nos invita a imaginar, cuando nuestra vida termina el cuerpo continúa su proceso de transformación a otros niveles moleculares en el cosmos, inserto en su tiempo y su contexto, con todo y la contaminación y las partículas que se mueven a través de él. Desde esta perspectiva, el cuerpo -como la tierra- ya no es definido como un territorio aislado, soberano, demarcado. Por el contrario, es un cuerpo impactado por la tecnología, interferido por implantes, un cuerpo marcado, perforado, colonizado, manipulado, tocado y profanado.

El cuerpo, por lo tanto, es un lugar de batallas, la soberanía es desplegada sobre él, la acción política se inscribe en él, las identidades y experiencias corren a través de él. El cuerpo, que está marcado por nuestros muchos traumas, lleva las marcas y las consecuencias de nuestro trabajo, nuestros contextos, nuestras decisiones y acciones. Sin embargo, aunque tal vez no nos demos cuenta, nuestro cuerpo nunca es estático, siempre está en proceso de transformación. Como lo señaló Spinoza, nuestra habilidad de actuar, lo que el cuerpo puede hacer, es también la medida de nuestro derecho natural y de nuestro potencial. Dependemos de nuestro cuerpo para nuestra 
existencia en esta vida, para nuestra producción creativa e intelectual, para nuestra vitalidad. El cuerpo marca no solamente nuestra habilidad para pensar, crear, y hacer, sino también nuestra habilidad para formar parte del devenir.
Como Mikko Tuhkanen nos recuerda, cuando Deleuze habló en el funeral de Michel Foucault el 29 de junio de 1984, leyó un pasaje del último libro de Foucault: El uso del placer. En este pasaje, Foucault hablaba de su pasión por encontrar nuevos conocimientos, y escribió:

\begin{abstract}
¿Qué es la filosofía hoy día... si no es la labor crítica que el pensamiento lleva a cabo sobre sí mismo? ¿En qué consiste, si no en la labor de conocer cómo y en qué medida podría ser posible pensar de forma diferente, en vez de legitimar lo que ya se sabe? (Foucault citado por Tuhkanen, 20052006, p. 1)
\end{abstract}

Esta pasión, que Deleuze compartía, fue lo que lo llevó a cuestionar nuestra tendencia "a subordinar la diferencia a la identidad para poder pensarla" (Deleuze, 1994, p. xv), y que lo llevó en su búsqueda por "una forma de liberar al pensamiento de esas imágenes que lo encarcelan" (Deleuze, 1994, p. xvii).

Tuhkanen argumenta que en sus últimos años, el acercamiento de Foucault a los conceptos queer abrió un espacio para "reformular la teoría queer separándose del Hegelianismo de la performatividad Butleriana $y$, sus consecuentes ( $y$ con frecuencia descartadas) políticas de reconocimiento" (Tuhkanen, 2005-2006, p. 1). Para Tuhkanen, el acercamiento al género del Foucault de sus últimos años era Deleuziano, a pesar de sus desacuerdos. Foucault escribió: "tenemos que trabajar en volvernos homosexuales y no ser obstinados en reconocer que ya lo somos" (Foucault citado por Tuhkanen, 2005-2006, p. 308). Esta declaración revela que Foucault se había separado de una construcción de la identidad que requería, y que dependía del reconocimiento del otro, hacia un proceso del devenir. Marca también la diferencia entre el cuerpo como un sitio sagrado que marca una identidad fija -soberana-, y el cuerpo desacralizado, uno que puede ser moldeado, penetrado, alcanzado e intervenido en su devenir.

En Inmanencia pura, Deleuze (2001) había argumentado que "una vida es la inmanencia de la inmanencia, inmanencia absoluta: es el poder completo, la felicidad completa" (p. 27). Siguiendo a Spinoza, Deleuze decía que "la inmanencia no es la inmanencia a la substancia; sino, que la 
substancia y sus modos existen en la inmanencia" (Deleuze, 2001, p. 26). Como resultado, para Deleuze, una vida, antes de que fuera definida como la vida de alguien, contenía todas las posibilidades del plano de la inmanencia, o en términos espinozianos, todas las potencialidades.
Spinoza se separó a sí mismo de una ética construida en base al bien y el mal, y en cambio, escribía sobre convenientia y disconvenientia, es decir, lo que es bueno para un sujeto, lo que no es conveniente para un sujeto. Deleuze se expresa de acuerdo con esta distinción y se imagina el potencial de una vida antes de la subjetividad:

Una vida de inmanencia pura (es) neutral, más allá del bien y el mal, porque fue únicamente el sujeto que la encarnaba en el meollo de las cosas que la hizo buena o mala. La vida de esta individualidad se diluye a favor de la vida singular inmanente de un hombre que ya no tiene nombre, a pesar de que no puede ser confundido por ningún otro. Una esencia singular, una vida... (Deleuze, 2001, p. 29)

Deleuze se separó del ámbito unido con la construcción kantiana de lo transcendental que estaba de la subjetividad. Así escribió:

Cuando el sujeto o el objeto que se sale del plano de la inmanencia se toma como un sujeto universal o como cualquier objeto al cual se le atribuye la inmanencia, lo transcendental es completamente desnaturalizado, porque entonces simplemente redobla lo empírico (como en Kant), y la inmanencia es distorsionada, porque entonces se encuentra encerrada en lo transcendente. La inmanencia no está relacionada con Algo como una unidad superior con todas las cosas o a un Sujeto como un acto que conlleva una síntesis de las cosas: es solamente cuando la inmanencia ya no es inmanencia de cualquier otra cosa sino de sí misma que podemos hablar del plano de la inmanencia. (Deleuze, 2001, p. 27)

En otras palabras, la construcción de una identidad fija, permanente, e incluso transcendental, es decir, una que sigue existiendo más allá de los límites impuestos por una vida, se lleva la posibilidad de imaginar un futuro fuera de los límites de esa identidad, se lleva la posibilidad de imaginar un futuro devenir más allá de los límites impuestos por el cuerpo y por la identidad. 
Rosi Braidotti construye sobre estas ideas a medida que se mueve más allá de la singularidad de una vida, a desmantelar el sujeto singular, para poder pensar una subjetividad colectiva. Este concepto de una subjetividad colectiva no fue elaborado como un sujeto organizado y conformado (siguiendo la tradición hegeliana) sino como la formación espontánea de una colectividad auto organizada. Esta fue una de las más importantes contribuciones del último (y nunca terminado) texto de Spinoza. Como Antonio Negri ha mostrado, El Tratado político de Spinoza presenta un argumento por un concepto de democracia que "no tiene una estructura contractual, que por tanto constituye un proceso que permanece tan abierto como la naturaleza del sujeto (multitude) que gobierna está incompleto" (Spinoza, 1951, p. 236). De hecho, para Spinoza un contrato (verbal o escrito) era meramente un regalo de palabras que por derecho natural podía romperse. El concepto de esta colectividad nómada que se forma, por tanto, no es contractual sino de una naturaleza espontánea. Está también atada a la idea de los derechos naturales, ya que la formación de una colectividad incrementa los derechos naturales de esta colectividad en formación. Según Spinoza (1951) "si dos se juntan y unen su fuerza, juntos tienen más poder, y en consecuencia, más derecho sobre la naturaleza que cada uno de ellos por separado, y mientras más hay que se unen en alianza, más derechos poseerán colectivamente" (p. 296).

Desafortunadamente, esta subjetividad colectiva, para Spinoza, estaba definida por el género, y excluía a las mujeres. Al final de su vida, Spinoza escribió en su Tratado político, sobre una versión de la democracia que todavía no se ha inscrito dentro de los espacios diagramados por la modernidad y que, por lo tanto, es espontánea por naturaleza. Sin embargo, en el último párrafo que Spinoza escribió en este mundo, construye un argumento en contra de la participación de la mujer en esa democracia espontánea:

Tal vez, alguien preguntará, ¿si las mujeres están bajo la autoridad de los hombres por naturaleza o por institución? Ya que si hubiese sido por simple institución, entonces no tendríamos una razón que nos lleve a excluir a las mujeres del gobierno. Pero si consultamos con la experiencia misma, nos damos cuenta que el origen de (esa dependencia) es su debilidad. (...) Uno puede decir con perfecta propiedad, que las mujeres no tienen por naturaleza derechos iguales que los hombres. (Spinoza, 1951, p. 387) 
Braidotti construye sobre el concepto spinoziano de una subjetividad colectiva al igual que sobre el concepto de nomadismo de Deleuze. Para ella, ser nómada "apunta a la descolonización del sujeto pensante" (Braidotti, 2011, p. 30). Esta colectividad nómada y espontánea forma "un nuevo lazo colectivo y transversal a través de múltiples procesos del devenir" (p. 36). Como Foucault lo dijo con respecto a la homosexualidad, el devenir no es un fin, sino un proceso que nunca se completa, y como resultado, según Braidotti
(2011), "el proceso de convertirse en nómada no es únicamente anti esencialista, sino asubjetivo, más allá de previas nociones de la individualidad. Es un modo transpersonal, finalmente colectivo. Uno nunca puede ser un nómada; uno solamente puede seguir intentando ser nómada" (p. 43). Pero el sujeto de Braidotti tiene género y es imaginado como un proceso de devenir en mujer, pues devenir en hombre es equivalente -para ellaen devenir en lo mismo en términos deleuzianos:

En la medida en que un hombre representa a la mayoría no hay un imaginario creativo o afirmativo en el "devenir en hombre": el sujeto dominante está atado a la carga del Ser auto perpetuante y de la unidimensional repetición de patrones existentes. (Braidotti, 2011, p. 29)

Ser mujer es una posición que en la terminología de Braidotti puede engendrar la diferencia deleuziana, y que simbólicamente representa otras posiciones que desconstruyen lo que ella Ilama las "identidades falogocéntricas." De esta manera, sostiene que: "Las distintas minorías empíricas (las mujeres, los niños, los negros, los indígenas, los animales, las plantas, las semillas, las moléculas, etc.) son los puntos de inicio privilegiados para el proceso activo y empoderador del devenir" (Braidotti, 2011, pp. 29-30). En otras palabras, la idea es imaginar devenir en otro. Por lo tanto, para Braidotti (2011):

Devenir en mujer es el punto de inicio necesario para la desconstrucción de las identidades falogocéntricas precisamente porque la sexualidad como institución está estructurada alrededor del dualismo de género y de su corolario -la posición de la mujer como desviada sexual, como la figura de la otredad- que son elementos constitutivos del pensamiento Occidental. (pp. 29-30) 
Como sabemos, Deleuze decía que una vida, antes de que la subjetividad diagramara sus límites, representa todas las posibilidades en el cosmos. El plano de inmanencia, para Deleuze, es congruente con la definición del caos que Deleuze y Guattari (1994) presentan en su último texto juntos, ¿Qué es la filosofía?, según ellos:

El caos es definido no tanto por su desorden como por la velocidad infinita con la que cada forma que obtiene dimensiones en él se desvanece. Es un vacío que no es una nada sino un campo virtual, que contiene todas las posibles partículas y genera todas las posibles formas, que surgen solo para desaparecer inmediatamente, sin consistencia ni referencia, sin consecuencia. El caos es la velocidad infinita del nacimiento y la desaparición. (p. 118)

Braidotti se mueve más allá del plano de inmanencia de "una vida" imaginado por Deleuze, y extiende el plano de inmanencia hacia la muerte y hacia el cosmos. Para Braidotti (2013), "La vida es energía cósmica, simultáneamente caos vacío y velocidad absoluta o movimiento absoluto. Es impersonal y es inhumana en el sentido monstruoso, animal de la alteridad radical: zoe en todos sus poderes" (p. 131). De manera similar para ella, "la muerte es también síntesis creativo de fluidos, energías, y perpetuo devenir" (p. 131).

De la misma forma, para Deleuze (2001) una vida:

No tiene en sí misma momentos, a pesar de estar tan cerca los unos de los otros, sino tiempo entre uno y otro momento, momentos entre ellos, no solamente surge ni pasa después, sino que ofrece la inmensidad de un tiempo vacío donde uno ve el evento que todavía no ha pasado y que ya ha ocurrido, en el campo absoluto de una conciencia inmediata. (p. 29)

Para Braidotti, la muerte es uno de estos eventos que "todavía está por pasar" y que a la vez "ya ha ocurrido desde siempre". Braidotti (2013) señala:

Como el evento que ya ha ocurrido desde siempre, la muerte es un evento constitutivo que está tras de nosotros; ya ha tenido lugar como un potencial virtual que construye todo lo que somos. El poder completo de estar 
percatado de la naturaleza transitoria de todo lo que vive es el momento que nos define en nuestra existencia. (pp.

Hay aquí una transformación en nuestra comprensión de temporalidad, ya que ella explica que "la muerte es el evento que ya ha ocurrido desde siempre al nivel de la conciencia" (p. 133). El cuerpo, por tanto, está desde siempre ya muerto, desde siempre en el proceso de devenir, desde siempre parte del cosmos. Para Braidotti (2013), la muerte es "la totalidad sobria del momento en que coincidimos completamente con nuestro cuerpo en devenir por fin en lo que hemos sido desde siempre: un cadáver virtual" (p. 133).

Pero yo inicié esta discusión diciendo que el cuerpo es una metáfora de la nación. Ya que el cuerpo es maleable, permeable, en un proceso de perpetuo devenir, hay algo más que puede aprenderse de esta metáfora. Tal vez que la solidificación de las identidades transcendentales busca frenar el proceso del devenir, significa que la construcción de la nación como un lugar que construye una identidad rígida e inamovible nos quita nuestras posibilidades para considerar el proceso del devenir que siempre ha estado operando, y no permite imaginar otras posibilidades para la nación.
Así como devenir en otro es un proceso que nunca puede completarse, pero que abre muchas posibilidades que nos permiten imaginar otras posibles versiones de nosotros mismos, otras potencialidades en nuestros cuerpos, otros posibles futuros, el proceso de devenir en otra nación nunca se completa, y en el proceso de devenir en la muerte, nuestra voluntad de aceptar dejar de ser uno o una tal como nuestra identidad lo define rígidamente, en este caso, cesando ser la nación que era definida rígidamente, podríamos tener la oportunidad de imaginar otros posibles futuros, otras posibles naciones, en nuestro proceso de devenir colectivo. A lo mejor podríamos dejar de experimentar un luto ante la pérdida de una identidad transcendental para nuestra nación. Tomando prestadas las palabras de Foucault; en cambio abrazar el proceso de devenir en nación, y no ser obstinados en buscar reconocimiento del que ya lo somos. Recordando las palabras de Braidotti; podemos buscar ser nómadas e imaginarnos a nosotros mismos vacando la idea de una nación rígida, para permitirnos imaginar devenir en otro, imaginarnos devenir en otra posible nación. 


\section{Referencias}

- Agamben, G. (2007). Profanations. Trans. Jeff Fort. New York: Zone Books.

- Braidotti, R. (2013). The Posthuman. Cambridge: Polity Press. . (2011). Nomadic Theory: The Portable Rosi Braidotti. New York: Columbia University Press.

- Butler, J. (1997). The Psychic Life of Power: Theories in Subjection. Stanford University Press.

- Carrillo-Rowe, A. (2004). Whose 'America'? The Politics of Rhetoric and Space in the Formation of U.S. Nationalism. Radical History Review (89), pp. 115-134.

- Deleuze, G. (1994). Difference and Repetition. Trans. Paul Patton. New York: Columbia University Press. . (2001). Pure Immanence: Essays on a Life. Trans. Anne Boyman. New York: Zone Books.

- Deleuze, G. and Guattari, F. (1994). What Is Philosophy? Trans. Hugh Tomlinson and Graham Burchell. New York: Columbia University Press.

. (1987). A Thousand Plateaus: Capitalism and Schizophrenia. Trans. Brian Massumi. Minneapolis: University of Minnesota Press.

- Foucault, M. (2003). Society Must Be Defended. Lectures at the Collège de France, 1975-76. Eds. Mauro Bertani and Alessandro Fontana. Trans. David Macey. New York: Picador.

- Negri, A. (1997). Reliqua Desiderantur: A Conjecture for a Definition of the Concept of Democracy in the Final Spinoza. Trans. Ted Stolze. The New Spinoza., pp. 218-246. Eds. Warren Montag and Ted Stolze. Minneapolis: Minnesota University Press.

- Spinoza, B. (1951). A Theologico-Political Treatise / A Political Treatise. Trans. R. H. M. Elwes. New York: Dover Publications.

- Tuhkanen, M. (2005-2006). Foucault's Queer Virtualities. Rhizomes, Cultural Studies in Emerging Knowledge, 11-12. Recuperado de http:// www.rhizomes.net/issue11/tuhkanen.html

- Wilson, P. (1994). Securing Out Nation's Borders. The Social Contract (Summer), pp. 280-282. (Discurso pronunciado en Los Ángeles el 25 de abril de 1994).

Nota

1 La traducción de las citas del inglés al español son de la autora. 